\title{
Cohort Learning For Graduate Students At The Dissertation Stage
}

\author{
Barbara D. Holmes, Argosy University, USA \\ Kimberly Birds, Argosy University, USA \\ Angela D. Seay, Argosy University, USA \\ Debra B. Smith, Argosy University, USA \\ Kimberly N. Wilson, Argosy University, USA
}

\begin{abstract}
Doctoral students discuss the power of collaborative cohort learning in transforming the dissertation phase of doctoral study. Innovative components of doctoral cohort learning and dissertation preparation are detailed.
\end{abstract}

Keywords: Cohort, Dissertation, Doctoral students

\section{INTRODUCTION}

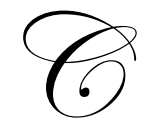

olleges and universities continue to struggle with how to get doctoral students to complete the dissertation in a timely and efficient manner. The current method of preparation oftentimes results in students floundering and taking years to write the dissertation. The dissertation experience is usually designed as an independent activity where the student investigator directs and manages the time and activities needed to bring the work to completion. Many doctoral students, however, flounder at the dissertation-stage of the process and are unable to accomplish the work. This study examines the perspectives of educational doctors who participated in a collaborative cohort while completing the dissertation in three academic semesters.

\section{THE COLLABORATIVE LEARNING COHORT}

Cohorts typically share a common path or group of experiences. Generally, in higher education, a cohort is admitted together in the program, classes are taken together and camaraderie is built over a period of semesters. The collaborative learning cohort simulates this in that there is an intersecting event where students come together and create the community of learning. The Writing for Research class is that intersecting place. It is in this class where students shared their writing, writing critiques, feedback, peer reviews and revisions. This openness helped students to become interdependent and work together as a learning community. It was a natural progression for students to want to move together as a cohesive group to the dissertation phase.

Cohorts, like communities, have traditions, mores, structures, and cultures that define them. Communities care for their members. The cohort is no different. The cohort community requires that the "ways of doing" and the "habits of mind" are acknowledged and respected. In this learning community, for example, it is important that all members be on time for learning. Work sessions are scheduled from 9:00 am to 5:00 pm on the scheduled class meeting weekends. It is expected that all students will be present and will work on tasks that are aligned with achieving identified goals during this scheduled time. Being present for work sessions conveyed respect for the process of the preparation model and for the commitment of other scholars in the group.

The collaborative learning cohort required a recognizable structure and learning discipline. In the collaborative cohort, it was quickly discovered that without structure and sustained guidance, students initially did lose focus, motivation, momentum and were unable to establish benchmarks to gauge their progress in completing the work. In order to address this dilemma, a new model of preparation was developed that embraced several very critical components: scheduled class time, structured and accountability measures, known benchmarks, collaborative 
learning community, self-regulating learning and strong advisor/chair involvement. Critical to the success of the model were the "expressed expectations" of the dissertation chair supported by regular assessments of benchmark attainment by each member of the cohort community.

Several doctoral students completed the dissertation in three academic semesters utilizing the collaborative learning cohort model. These new doctors offer empirical evidence about what has been learned from having dissertation stage students' shift from independent to collaborative learning. Completing the work was the clear priority of the collaborative cohort experience.

\section{COACH THE COHORT TO CLIMB THE MOUNTAIN}

Writing a dissertation is like climbing a huge mountain. Participation in the collaborative cohort as a veteran principal of an elementary school required the ability to first relinquish power. The writer lacked the experience for preparing to climb a mountain. While a leader in the normal school setting, the writer knew nothing about mountain climbing. In this instance and under these circumstances, it was of critical importance to be lead by an experienced guide, to have knowledgeable companions and to have a base camp, a place to return to when the trail became treacherous and unwieldy. The collaborative cohort was base camp.

Within the Cohort, there were knowledgeable leaders. Members of the Cohort were conditioned to leave attitudes, titles, and other responsibilities outside of the Cohort and function as a team with a purpose and a mission. At every stage of the climb, the experience of the individual team members emerged to provide solid guidance for the fellow travelers. Some knew theoretical frameworks, some knew methodology, and others knew SPSS and so on. Cohort participants were trained to accept the knowledge being offered, question that which was not understood, challenge the process with individual perspectives and offer constructive feedback without lowering the self-esteem of others.

This huge mountain was going to be there. Getting to the peak of the mountain was our daily mantra. It was understood that it would take endurance, planning, time management, proper equipment, organization, support, and relentless training and practice. The most important tool for a successful climb is an experienced guide, in this case, a committed chairperson who was also a competent and supportive taskmaster. Mountain climbers need a leader who is willing to give of their time and talents and who is able to lead with compassion and encouragement.

Teach-the-teacher model was also effective. No one was allowed to go forward unprepared. As in mountain climbing, one needed to know, and understand, where to climb, climbing preparation, specific techniques and utilization of the right tools. Doctoral students were able to learn this from each other. Once a member of the Cohort had an experience that others may encounter later, that experience was shared with the entire Cohort as well as the Writing for Research Students who were enrolling in Dissertation for the upcoming semester. This is an example of Blooms Taxonomy's Highest Level of Critical Thinking...."Evaluation". When you are able to re-teach a concept or skilled learned, it strengthens your own level of knowledge and skills.

Student collaboration proved to be the most effective tool used to move students successfully through the doctoral program. The seamless connections and relationships among the students held the cohort together. Students encouraged each other to stay on task, be accountable for the results, work through setbacks and challenges, and most importantly, stay focused on conquering the mountain.

\section{LIVING THE COHORT EXPERIENCE}

Even under normal circumstances, completing a dissertation is a colossal undertaking by doctoral candidates. This task encompasses endless days and nights. In other words, there is no rest for the weary. The process of completing a dissertation can be a very lonely road and at times a battle that seems never-ending. However, with the support of the collaborative cohort, the goal to complete a dissertation becomes more obtainable. Living the cohort experience involves working with a group of people to complete a similar task. This communal experience decreases frustrations, unites a community of learners and enables the group to stay focused on the uniting purpose. This support system provides staying power when times become difficult and perplexing. 
Participating in the cohort to complete my dissertation strengthened my ability to represent what a true doctoral candidate should symbolize. Even in a cohort, writing the dissertation has not been an easy road, but anything worth having requires hard work, desire, and dedication. In the end, it generated pride in the quality of the final product

The weekend cohorts have been designed as professional learning communities, where all of the doctoral candidates come together and partake in seminars needed to strengthen writing, communication and presentation skills. The cohort seminars were beneficial because, for many, it reinforced data and information learned during doctoral coursework, but may not have really grasped until it was time for us to apply it to the dissertation experience. For example, one of the cohort workshops provided a refresher on research methodology. This afforded many candidates, including myself, the opportunity to gain a better insight of the process, reexamine the quality of the proposed research questions and focus on the specific type of analysis required to examine the questions being asked.

Learning to embracing others in the spirit of learning has been one of the real outcomes of our cohort. Candidates and scholars freely shared their knowledge and each was able to obtain some degree of wisdom and guidance. This resulted in a most powerful form of learning that I will never forget, and will incorporate in my professional career. Reaching back to help someone else is the motto of the group. This profound action is exemplary of what a true person of excellence strives to accomplish.

In the collaborative learning cohort, participants gained the power to continue beyond the obstacles and develop personal inner-strength within this supportive environment. Students were able to stay the course, accept feedback and advice, and make the necessary changes. Working with a team in collaboration was a factor in continuing to strive to reach the goals. It is so much easier to face adversity when others in your circle can relate to your frustrations and encourage you to strive further. In times like these, we were comforted by the words of John Maxwell:

"When we are foolish we want to conquer the world. When we are wise we want to conquer ourselves".

\section{COHORT AS COLLABORATIVE COMMUNITY}

The collaborative learning cohort represents team in the best sense of the word (Together Each Accomplished More). Although each member is responsible for his or her own work, each is also responsible for contributing to the success of other members. In this learning community, each person has a role and a contribution to make. There were no excuses for failure, because our cohort consists of motivating and supporting members of the learning community.

As a cohort, we established traditions. These traditions were built around the concepts of Time, Task, Teach, and Transform. The members reached consensus on parameters and guidelines that were conducive and rational. Just like any other team structure, each member had responsibilities not only for personal achievement, but also for the achievement of others.

Time. Cohort member recognized the importance of time as a core value of the process. Each member had an individual timetable for work completion and the cohort had time commitments to each other that needed to be honored. Cohort members were also aware that the lack of good time management was one of the major reasons why doctoral students fail to complete their work.

Task. Time on task is a requisite for effective learning. Students in the cohort had to be working on the dissertation in a sustained fashion to make forward movement. This focus on the task at hand enabled each student to make individual progress and report out results of the week's work to the collective body.

Teach. Cohort members took pride in focusing on helping others succeed. By doing so, individual and collective goals were achieved. Each member always contributed to the group. We followed the model of our Chair who demonstrated and expected superior performances at all times. Displaying expected actions deemed rewarding on a daily basis and each member followed those guidelines. 
Transform. Our cohort community really cares for each other. We worked well together and we took care of each other. Participants collaborated during work sessions, and communicated via telephone and or e-mail at least two to three times per day. We transformed ourselves into a close knitted, professional family who worked well together for the success of the group. Our "ways of doing" things are different from the usual or traditional class sessions. We continued to work independently during times when we were away from the campus, yet we remained connected through emails and telephone calls.

When working to achieve a goal that is as prestigious as earning a doctorate degree, sacrifices must be made, the road is not easy to tread, and sometimes things do not take place, as we would want them to. Being the family oriented group that we are, there are members whose areas of strengths includes motivating, listening, encouraging, and sharing to help with overcoming the outside challenges that any member would encounter. The workload seemed manageable when conversation regarding the process could be discussed with members who were experiencing the same or similar challenges. Just like any other family, the cohort worked together to reach a common goal. We sometimes lived together, we had meals together, we laughed, we cried, and sometimes we did not always agree. However, we always worked things out, by remembering that together each member accomplishes more. This constant flow of support was critical to our success. The class agreed that constant support was needed and that the class needed to stay together and meet on a regular, scheduled basis.

\section{COHORT AS COLLABORATION}

The very nature of cohort suggests working together in some fashion. Strength in this learning community emerges from working together in a collegial and collaborative manner. The value added for mutual learning is that candidates assimilate knowledge and perspective from each other and growth occurs. This enables candidates to see their work through multiple lenses: the perspectives of other dissertation students.

Improving the work is the clear priority of the experience. Collaboration with other learners helps students to identify barriers to their own learning and establish a plan for improving the work product. The mantra to "just do the work" resonates throughout the cohort from multiple voices that are not only instructor originated. At the core of this experience is a very basic concept and underlying assumption: by helping others, we help ourselves as well. Having just read John Maxwell's book, Talent is not Enough, the concept of everyone being "teachable" became critical to the underlying philosophy of the collaborative cohort.

Being Teachable involves humility. The cohort represented a group of powerful and knowledgeable members in respective disciplines and fields. None, however, experienced the path to earning a doctorate. By being humble in the face of superior knowledge, students were able to let their mask down and share with the group individual weaknesses in order to receives assistance from others.

This dissertation experience has been an invaluable journey and opportunity. Throughout all of the obstacles, the most significant lesson learned was understanding the importance of being "teachable." According to John Maxwell, "The most important skill to acquire is learning how to learn." Learning and being teachable is an iterative process. It requires commitment, discipline, and initiative. Through our results-oriented cohort model, a learning community evolved that focused on commitment, communication, collaboration, and learning.

For many of the doctoral candidates, the idea of being a student was a challenging task. Many of the candidates held leadership positions and titles within their professional careers and had a difficult time accepting constructive criticism. However, through our dissertation chair's situational leadership style, consistency, and fortitude, we realized very early that she had the passion, willingness, and knowledge needed for guidance in completing our dissertations. The cohort model for classroom expectations were conveyed with conviction and a sense of pride when she communicated the courses overview, objectives, personal vision, clear expectations, and goals to help all of the candidates who were "teachable" achieve the ultimate goal of completing dissertation phases. The candidates were required to submit weekly revisions, review shelf and online dissertations, attend the university's writing lab, conduct peer reviews of papers, share theoretical frameworks, find research, facilitate mock dissertation proposals and attend scheduled final dissertation defenses. This process offered unlimited opportunities for formal and informal learning. As candidates began taking ownership of their learning, reciprocity, and cooperation made writing the dissertation "a doable accomplishment." 
As self-regulated learners, facilitators, and leaders, it was a common goal to ensure everyone's success. Candidates made personal choices to commit to doing the work by not allowing excuses, such as procrastination to keep them from accomplishing the tasks of earning a Doctor of Education Degree. Therefore, there were biweekly scheduled meetings to make sure consistent progress was made on each individual's research. Additionally, during those meetings students received vital information on the Institutional Review Board procedures, methodology research suggestions, and instructional lessons on understanding Statistical Package for Social Sciences. Through this results-oriented model, success was expected and attained.

The author postulates that all goals are attainable with commitment, initiative, and a willingness to learn. There is a positive correlation between being teachable and success. For those that deny themselves the opportunity to be teachable, they diminish the ability to maximize their learning potential. As university's and professors, seek best practices and researched-based interventions to improve all but dissertation (ABD) ever-increasing statistics, promoting cohorts is a supportive strategy that infuses collaboration and student success.

\section{COHORT AS ACCOUNTABILITY} and embrace:

This collaborative cohort community has identifiable benchmarks that every student is able to recognize

Benchmark 1 - Development of a viable and researchable topic

Benchmark 2 - Development of a solid chapter 1 with a coherent theoretical framework, statement of purpose and problem statement

Benchmark 3 - Development of well constructed research questions with the alternate hypotheses clearly articulated

Benchmark 4 - Development of a properly formatted paper with $100 \%$ adherence to APA format, $5^{\text {th }}$ Edition

Benchmark 5 - Development of chapter 2 with 40 pages of well-reasoned research. The introduction provides an organizational schema for the chapter and the summary captures the essence of the related literature

Benchmark 6 - Development of chapter 3 with documentation that the research committee has reviewed it. Chapter 3 has a solid research design appropriate to the study and a proposed methodology to conduct the study. The research design matrix has been submitted and approved.

Benchmark 7 - Development of chapters 4 and 5. Evidence that the paper has been proofread for sentence structure, organizational coherence, grammatical and mechanical errors.

Benchmark 8 - Presentation of a paper that has been reviewed by the Writing Lab with all suggested revisions and corrections addressed.

Benchmark 9 - Development of a succinctly prepared PowerPoint presentation that summarizes and presents the proposed research

Benchmark 10 - Delivery of an articulate and well-presented mock defense presentation that provides evidence that the candidate can professionally share the proposed research with the professional community.

Students are able to be self-regulated learners in this environment because the expectations have been made clear and are articulated often. Students know what the benchmarks of progress are and are exposed to a study discipline that, if followed, will enable them to reach each benchmark. It is this structured approach that has enabled students' to stay on point with their dissertation progress. Even the students who slack off are still cognizant of what must be done in order to progress forward and are able to gauge their success or lack thereof. 


\section{TEN PRINCIPLES OF COLLABORATIVE COHORT LEARNING}

In summary, the essential components of this collaborative learning cohort approach are reflected in the following principles:

1. Cohort engagement occurs when the cohort is an intentional and deliberate assemblage of learners with a specific and common purpose.

There are no "accidental" learners in the cohort. Membership in the cohort is purposeful and members set out to share a common set of learning experiences. Only those persons who share the stated goals of the cohort agree to participate in this planned and purposeful learning experience.

2. Central to the effectiveness of the cohort is the idea of "expressed expectations". Expectations under girding the cohort must be clearly stated and understood by all who participate. These expectations must be expressed often and must be expressed clearly. Expressed expectations become the guiding rules for the behavior and productivity of cohort participants. With rules clearly known, the cohort becomes a community of self-regulating learners.

3. Significant attention must be given to the creation of "community" within the cohort and among cohort members.

The idea of community connotes a collection of people who agree to share common interests, traditions and purposes. The community has ownership of the quality of life in this shared place. So it is with the cohort. The cohort community must be self- governing in its adherence to agreed upon goals and objectives. Life in the cohort is good for all when all contribute to the common good.

4. Clearly identified benchmarks of performance must guide the work process and product.

Optimal performance is achieved when standards and benchmarks are known. These standards and benchmarks represent clear measures of the work and what has been accomplished. Students themselves can assess individual performance against the benchmarks that guide the process. Students can then make more informed decisions about where they are in the process and what they have to do to achieve peak performance.

5. Cohorts must enable individual responsibility and accountability to the group as a whole.

Cohort communities believe in the axiom, "Reach back to help someone!" As students progress through the dissertation process, goals are accomplished. Individual responsibility in completion of those goals prepares each student to be able to assist the candidates in the pipeline. The spiraling effect of this seamless transition provides all students with the community privilege of receiving suggestions and assistance from those ahead in the accomplishment of benchmarks and extending a helping hand to those behind.

6. Effective cohorts must have structure, so that participants understand how they are to work. Establishing expectations and timelines provides basic structure to the cohort experience. Expectations include regular attendance and participation in all classes, timely completion of assignments, regular communication with the chair and committee members, positive attitudes, and graceful acceptance of suggestions, and helpful critiques for fellow students. In addition, timelines and class time are essential in providing a structure to the process.

7. Cohorts are most engaged when a discipline of learning is evident with the clear purpose of accomplishing "the work".

Collaboration encourages inspiration, commitment, determination, and quality in cohort members. Participants focus on accomplishing the task. In addition, a drive for quality is evident. Answering to self, the instructor, and fellow students inspires cohort students to attend to the goal.

8. Cohorts foster using the strengths and intellectual gifts of the individual to help fulfill the purposes of the learning community.

Each participant in a cohort contributes to the benefit of the group in individual ways. Some students provide the organizational strength needed to communicate cohesiveness to all. Others contribute a sense of humor and positive attitude. Students with Microsoft Word, PowerPoint, research or SPSS abilities are invaluable to others. Participants with strong writing skills readily share those talents. Proofreading is also a valuable skill shared within the group. All the skills contributed from Cohort members establish the consistent collaboration within the group. 
9. Cohorts require individual and collective commitment and high task engagement.

Engagement encourages individuals to excel academically. Participants eagerly accept the rigor of group challenges, knowing that all will collaborate to reach high standards. As each one contributes individual commitment, the cohort excels.

10. Cohorts must put into place the "enabling conditions" to help each learner accomplish his or her best work.

"Students learn what they live!" This true maxim is pertinent to Cohort productivity. The instructor of a cohort models exceptional leadership qualities by establishing conditions that enable each student to embrace rigor and excellence. The cohort provides a place where each student's learning style can be addressed through the activities that are inherent in this collaborative learning paradigm.

\section{REFERENCES}

1. Barnett, B. G., Basom, M. R., Yerkes, D. M., \& Norris, C. J. (2000). Cohorts in educational leadership preparation programs: Benefits, difficulties, and the potential for developing school leaders. Educational Administration Quarterly, 36(2).

2. Bolman, L. G., \& Deal, T. E. (2003). Reframing organizations: Artistry, choice, and leadership (3rd ed.). San Francisco: Jossey-Bass.

3. Clark, D. C., \& Clark, S. N. (1997). Addressing dilemmas inherent in educational leadership preparation programs through collaborative restructuring. Peabody Journal of Education, 72(2).

4. Donaldson, J., \& Petersen,G (2007). Cohort doctoral preparation programs: Neo-Institutional Perspectives, National Council of Professors of Educational Administration, Connexions Project.

5. English, F. W. (2006). The unintended consequences of a standardized knowledge base in advancing educational leadership preparation. Educational Administration Quarterly, 42(3).

6. Guthrie, J. W., \& Sanders, T. (2001, January 7). Who will lead the public schools? The New York Times, $4 A, 46$.

7. Hart, A. W., \& Pounder, D. G. (1999). Reinventing preparation programs: A decade of activity. In J. Murphy, \& P. B. Forsyth (Eds.), Educational Administration: A decade of reform (pp. 115-151). Thousand Oaks, CA: Corwin Press Inc.

8. Levine, A. (2005). Educating School Leaders. Washington, DC: The Education Schools Project.

9. Maxwell, J. (2007). Talent is never enough. Nashville, TN: Thomas Nelson, Inc.

10. Saltiel, I. M., \& Russo, C. S. (2001). Cohort programming and learning: Improving educational experiences for adult learners. Malabar, FL: Krieger.

11. Scribner, J. P., \& Donaldson, J. F. (2001). The dynamics of group learning in a cohort: From non-learning to transformative learning. Educational Administration Quarterly, 37(5.

12. Shulman, L. S., Golde, C. M., Bueschel, A. C., \& Garabedian, K. J. (2006). Reclaiming education's doctorates: A critique and a proposal. Educational Researcher, 35(3).

13. Young, M. D., \& Petersen, G. J. (2002, Winter). Enabling Substantive Reform in the Preparation of School Leaders. Educational Leadership Review, 3(1). 
NOTES 